\title{
Pattern of Haematological Disorders in a Tertiary Diabetic Hospital: A Pilot Study
}

\author{
DT FARHANA $^{\mathrm{a}}, \mathrm{N}^{\text {QUAMRUN }}{ }^{\mathrm{b}}, \mathrm{C} \mathrm{SUBHAGATA}^{\mathrm{c}}$
}

\begin{abstract}
Summary:
Background: Patients with diabetes mellitus may suffer from various haematological diseases. $A$ one year prospective study from July 2007 to July 2008 was done in the Department of Transfusion Medicine of BIRDEM to see the distribution of haematological diseases among the referred patients.
\end{abstract}

Objective: The aim of the study was to observe the pattern of hematological diseases in patients with diabetes mellitus.

Materials and Method: A total number of 111 new cases suffering from various haematological disorders were included in this observational study for one year duration from July 2007 to July 2008. Patients were diagnosed by peripheral blood film, complete blood count, bone marrow, hemoglobin electrophoresis. History of the patients including clinical informations were recorded with written consent from their very first arrival.

Results: Among the studied 111 patients, 23 (20.72\%) were suffering from various types of haemoglobinopathies and $88(79.28 \%)$ with other haematological diseases. When glycemic status was considered $65(58.56 \%)$ patients out of 111 showed diabetes mellitus along with haematological diseases. Among those diabetic patients 11\% had haemoglobinopathies, 25\% had bleeding disorders, autoimmune diseases and marrow aplasia, 27\% suffered from deficiency anaemia, anaemia of chronic diseases and haemochromatosis, where as 37\% had various clonal haematological malignancy. Among

Introduction

The growing problem of haematological diseases \& diabetes mellitus are indicative of globally increasing trend of non-communicable diseases. Diabetes and

a. Dipta Tashmim Farhana, FCPS ( Haematology), MTM (Transfusion Medicine), Assistant Professor \& Head, Transfusion Medicine Department, BIRDEM.

b. Quamrun Nahar, PhD, Senior Research officer, Department of Biochemistry and Cell Biology, BIRDEM.

3 Subhagata Choudhury, FCPS, M.Phil, Director Laboratory Services, BIRDEM

Address of Correspondence: Dr. Tashmim Farhana Dipta, FCPS (Haematology), MTM (Transfusion Medicine), Assistant Professor \& Head Transfusion Medicine Department, BIRDEM and Ibrahim Medical College, Phone: 01817049343, e-mail: tashmim@yahoo.com Received: 22 February, 2009

Accepted: 7 July, 2009 haemoglobinopathies group, beta thalassaemia major was $21.74 \%$, beta thalassaemia trait $47.83 \%$, haemoglobin Etrait $17.39 \%$ and haemoglobin E-disease was $13.04 \%$. Out of 23 Haemoglobinopathy patients 14 (60.87\%) were male and $9(39.13 \%)$ were female. Out of 88 patients with other haematological diseases except haemoglobinopathy 26 (29.54\%) were of various haematological malignancies, $16(18.18 \%)$ were of bleeding disorders, autoimmune diseases and marrow aplasia and 47 (53.41\%) out of 88 patients had deficiency anaemia, anaemia of chronic diseases and haemochromatosis. In this group 40 patients (45\%) were male and 48 (55\%) patients were female.

Conclusion: This study shows majority patients with haematological diseases were suffering from diabetes mellitus. Among the haemoglobinopathies group, male were predominant and among the other haematological diseases except haemoglobinopathies group, female were predominant. From this study we suggest further multicentred study to see any precipitating cause between haematological diseases and diabetes mellitus. There is also an immense need to maintain registry of haematological diseases with a plan to establish state of art haematology services in all tertiary specialized hospitals including BIRDEM.

Key words: haemoglobinopathy, clonal hematological malignancies, anaemia, bleeding disorder, diabetes mellitus, cancer

(J Bangladesh Coll Phys Surg 2009; 27: 148-154)

cancer are two conditions that individually overwhelm both patients and clinicians. Approximately $8-18 \%$ of people with cancer have diabetes ${ }^{1}$. Patients with diabetes and cancer have poorer prognosis compared with those without diabetes $^{2}$. Diabetes and hyperglycaemia are associated with higher infection rates, shorter remission period and shorter median survival times as well as higher mortality rates ${ }^{2-6}$. Researchers hypothesize that exposure to hyperglycaemia, elevated insulin concentrations and the growthpromoting effects may stimulate the development of progression of cancer ${ }^{2}$. In haematological malignancy normal bone marrow haemopoiesis is 
often disrupted due to infiltration of clonal tumor cell growth ${ }^{7}$. The treatment and therapies for diabetes in the setting of cancer present a major challenge for clinicians ${ }^{2}$. Haematological malignancies constitute approximately $7 \%$ of all cancer cases in Sweden and leukaemia in that country is the most common malignancy among children ${ }^{7}$. Study shows that approximately 150 million people have diabetes mellitus world wide and this may double by $2025^{8}$, where as the role of diabetes as a risk factor for cancer is still uncertain ${ }^{9}$.Various study shows there is an increased risk for development of cancer among diabetes $^{6,10}$ and vice versa ${ }^{11}$. Cancer is the second most killer in the world after cardio-vascular diseases ${ }^{12}$. About $13 \%$ of all death in the world is currently caused by cancer; where as in 2007 about $6 \%$ patient suffering from diabetes which is growing as a silent killer ${ }^{12}$. Study shows there is an association of abnormal glucose metabolism, higher body mass index and risk of haemopoietic cancer like leukaemia, multiple myeloma ${ }^{11}$.Previous study suggested that, diabetes mellitus a frequent cause of renal insufficiency ${ }^{13}$ also causes more activation of prothrombotic markers in acute myeloid leukaemia or disseminated intravascular coagulation ${ }^{14}$. In acute lymphoblastic leukaemia secondary to chemotherapy, transient hyperglycaemia develop due to consequence of insulin resistance, induced by glucocorticoid, as well as, due to decrease insulin synthesis by Lasparaginase $\mathrm{e}^{15-17}$ and occurs in $4.4 \%$ of patients with acute lymphoblastic leukaemia ${ }^{16}$; whereas, episode of infection is more in other leukaemia ${ }^{18,19}$. On the other hand, iron deficiency is the most common cause of anaemia affecting about 500 million people ${ }^{20}$. Study shows iron deficiency anaemia and anaemia of chronic disease are common in diabetic patients ${ }^{20}$ and is associated with increased morbidity, mortality and poorer prognosis in diabeticassociated co morbid conditions ${ }^{18-20}$. Diabetes occurs in hereditary haemochromatosis and transfusional haemosiderosis due to insulin deficiency, resistance ${ }^{21}$ and excessive iron deposition ${ }^{22-24}$. Study shows using iron chelating agent 21,25 and blood donation 21, 25 decrease development of diabetes in such patients. Where as, chronic autoimmunity is associated with autoimmune haemolytic anaemia, idiopathic thrombocytopenic purpura 26,27 and obesity ${ }^{26-30}$ which increase the risk of myeloma among older and influences chronic myeloid leukaemia and Hodgkin's lymphoma 26-29; all these show association with diabetes $^{26-30}$. Persons with haematological malignancies such as leukaemia, lymphoma especially with extranodal lymphoma ${ }^{33},{ }^{34}$ or myeloma and blood dyscrasias often have coexisting diabetes mellitus 26-34, 36. Study shows chronic lymphocytic leukaemia, which is $20-30 \%$ of all leukaemia $^{32}$ and diabetes mellitus both causes suppression of immune system, hyperglycaemia and higher risk of infection among diabetic ${ }^{18,19,37}$.

In USA the most common haematological malignancy among the child up to 14 years is leukaemia ${ }^{37}$. In United States there is increasing trend of cancer and prevalence among female is $0.3 \%$ with non-Hodgkin's lymphoma is $4 \%$ and leukaemia is $3 \% 37$. Whereas, previous studies suggested that among haemoglobinopathies, prevalence of thalassemia is $16 \%$ in Cyprus, $3-14 \%$ in Thailand, and 3-8 \% in populations from India, Pakistan, Bangladesh and China ${ }^{38-40}$. A lower prevalence shown in Africa $(0.9 \%)$ and northern Europe (0.1\%) 38. Worldwide, $\mathrm{Hb}$ E-beta-thalassemia is most frequent and the incidence of $\mathrm{Hb}-\mathrm{E}$ approaches $60 \%$ of the populations in many regions of Southeast Asia $^{39}$. As a growing global public health problem in the next 20 years an estimated 900,000 births of clinically significant thalassemic are expected to occur ${ }^{39}$. In Bangladesh a conservative World Health Organization (WHO) report estimates that, about $3.0 \%$ of populations are carriers of beta thalassemia and $4.0 \%$ are carriers of $\mathrm{Hb}-\mathrm{E}^{40}$

There is dearth information regarding haematological disorders among the diabetic patients in Bangladesh. So this pilot study was designed to see the prevalence of diabetes mellitus and pattern of haematological diseases among patients attending BIRDEM (Bangladesh Institute of Research and Rehabilitation in Diabetes, Endocrine and Metabolic Disorders).

\section{Methodology:}

In this observational study, one hundred and eleven patients between fifteen to ninety years of age, suffering from various haematological disorders reported academically in the Transfusion Medicine Department of BIRDEM as out patient or indoor 
referral cases. Patients were diagnosed previously for various haematological diseases with modern equipments and special emphasis was given on peripheral blood film (Leishman's stain), complete blood count (automated cell counter: Sysmax XT1800i, model Japan.), bone marrow (marrow puncture needle: Salah), haemoglobin electrophoresis (Sebia: France, Hydragel Heamoglobin -E: K-20) and coagulation profile (Prothrombin time: Start Diagnostic Stago, Activated Partial thromboplastine time: COAG-A-Mate XM) done in BIRDEM laboratory division and Haematology Department of BSMMU ( Bangabandhu Seikh Mujib Medical University). Histories of the patients including clinical information's were recorded with written consent from their very first arrival. Only new cases were enrolled in this study, those were referred to the Department of Transfusion Medicine as a part of consultation from various out patient clinics and inpatient departments of BIRDEM. Study period was one year from July 2007 to July 2008. Data were analyzed using Microsoft office excel 2003 for Windows version.

\section{Results:}

Total number of 111 patients between fifteen to ninety years of age, suffering from various haematological disorders reported in the Transfusion Medicine Department of BIRDEM as out patient or indoor referral in BIRDEM. 65 patients out of $111(58.56 \%)$ showed diabetes mellitus along with haematological diseases. That means majority patients showed diabetes mellitus along with benign or malignant haematological diseases. In the group of 88 patients $(79.28 \%)$ with other haematological diseases except haemoglobinopathy $25 \%$ patients were of bleeding disorders, disseminated intravascular coagulation and autoimmune haemolytic anaemia had diabetes mellitus; $27 \%$ patients with deficiency anaemia, haemochromatosis and marrow aplasia had diabetes mellitus; where as $37 \%$ patients with clonal malignant haematological diseases were suffering from diabetes mellitus was shown in figure no-1. Among patient in this group, 30.68\% which was majority (27 patients), were suffering from iron deficiency anaemia and next highest was $17.04 \%$ with anaemia of chronic diseases. Among them, 55\% (48 patient) were female and $45 \%$ (40 patient) were
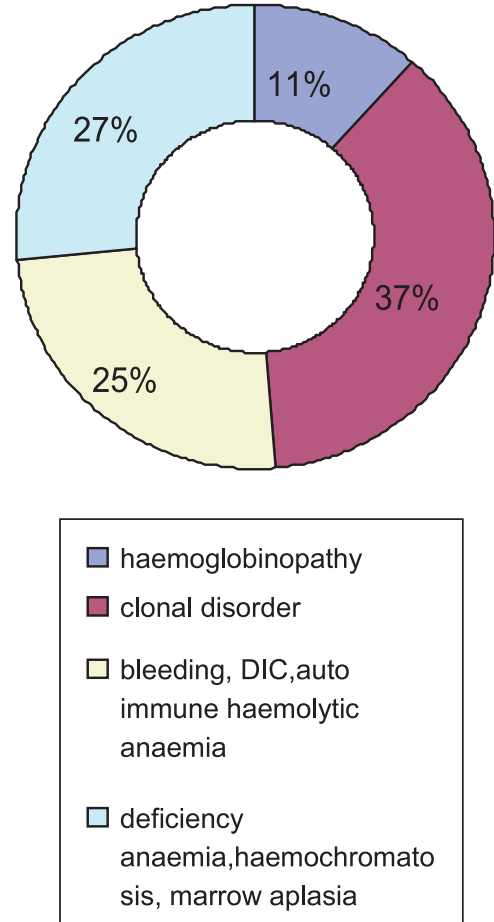

Fig.-1: Shows distribution of patient with diabetes mellitus $(N=65)$

$11 \%$ in haemoglobinopathy group, $25 \%$ patients with bleeding disorders, disseminated intravascular coagulation and autoimmune haemolytic anaemia, $27 \%$ with deficiency anaemia, haemachromatosis and marrow aplasia patients and 37\% patients with clonal malignant diseases were suffered from diabetes mellitus.

male, so female were higher in this group. According to the disease pattern male were predominantly suffering from anaemia of chronic disease, haemophilia, polycythaemia, megaloblastic anaemia, Hodgkin's and non-Hodgkin's lymphoma, haemochromatosis, acute myeloid leukaemia , acute lymphoblastic leukaemia and chronic myeloid leukaemia. Where as, in female, iron deficiency anaemia, autoimmune haemolytic anaemia, abnormal bleeding or disseminated intravascular coagulation, idiopathic thrombocytopenic purpura, multiple myeloma, chronic lymphocytic leukaemia, aplastic anaemia, myelodysplastic syndrome group were predominant. In this group of 88 patients, 26 (29.54\%) patients were suffering from various clonal haematological malignancies eg. polycythaemia 
rubra vera, Hodgkin's diseases, non-Hodgkin's lymphoma, multiple myeloma, acute myeloid leukaemia, acute lymphoblastic leukaemia, chronic myeloid leukaemia, chronic lymphoblastic leukaemia, myelodysplastic syndrome. 16 patients $(18.18 \%)$ with bleeding disorders e.g. haemophilia, abnormal bleeding or disseminated intra vascular coagulation, autoimmune diseases, idiopathic thrombocytopenic purpura, aplastic anaemia or marrow aplasia and $47(53.41 \%)$ patients were of deficiency anaemia e.g. iron deficiency anaemia, megaloblastic anaemia, anaemia of chronic diseases and haemochromatosis. Among 88 patients one female patient had both iron deficiency anaemia and multiple myeloma. All these three categories of patients were elaboratively distributed in figure no-2, 3 and 4 and total distributions of 88 patients according

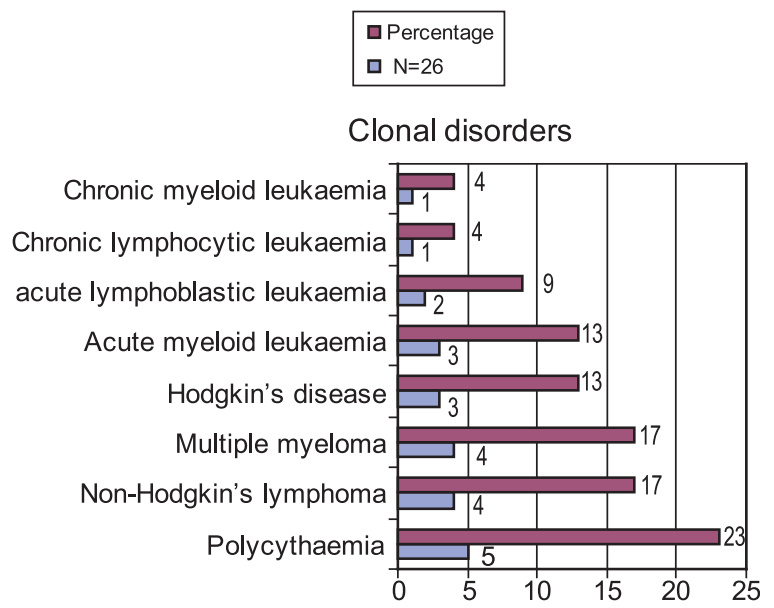

Fig.-2: Distribution of clonal haematological malignancies only $(N=26)$.

to diseases were shown in table no-1. Highest age among these patients was in between 50-60 years of age group (21.59\%) and next $20.45 \%$ were in between $60-70$ years of age group. On the other hand, 23 patients out of $111(20.72 \%)$ were suffering from various types of haemoglobinopathy. Among them beta thalassaemia major $21.74 \%$, beta thalassaemia trait $47.83 \%$, haemoglobin E-trait $17.39 \%$ and haemoglobin E-disease $13.04 \%$ were shown in table no-II. Out of 23 haemoglobinopathy patients, 14 $(60.87 \%)$ were male and $9(39.13 \%)$ were female. In this group male patients were predominantly suffering from haemoglobinopathies. Among these
Bleeding disorders, autoimmune diseases and marrow aplasia

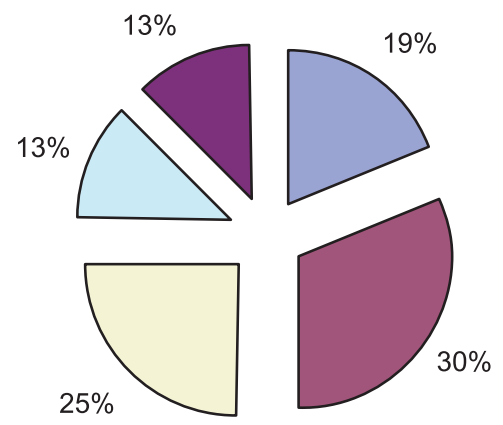

$\square$ haemophilia

$\square$ Abnormal bleeding /Disseminated intravascular coagulation $\square$ autoimmune haemolytic anaemia

$\square$ idiopathic thrombocy topenic purpura

$\square$ aplastic anaemia

Fig-3: Distribution of bleeding disorders, autoimmune diseases and marrow aplasia $(N=16)$.

\section{Deficiency anaemia,anaemia of chronic diseases and haemochromatosis}

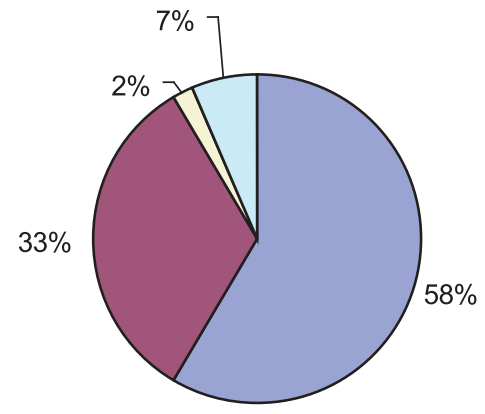

\section{$\square$ iron deficiency anaemia $\square$ anaemia of chronic disease $\square$ megaloblastic anaemia haemochromatosis}

Fig.-4: Distribution of deficiency anaemia, anaemia of chronic diseases and haemochromatosis $(N=47)$.

male patients $43 \%$ had beta thalassaemia trait , $29 \%$ had beta thalassaemia major, $21 \%$ were suffering from haemoglobin $\mathrm{E}$ trait and $7 \%$ had haemoglobin $\mathrm{E}$ diseases; where as among the female $56 \%$ had beta 
thalassaemia trait, 22\% had haemoglobin E diseases and $11 \%$ had either beta thalassaemia major or haemoglobin $\mathrm{E}$ trait. In case of age distribution highest number of patients with haemoglobinopathy was $60.87 \%$ in 20-30 years of age group. In this group diabetes mellitus was $11 \%$, shown in figure no1. On the other hand, among total patients, 46 were non-diabetic. Among them 31(67\%) were male and $15(33 \%)$ were female.

\section{Table-I}

Distribution of other haematological diseases except haemoglobinopathy. $(N=88)$

Name of the disease

Number Percentage

\begin{tabular}{lll}
\hline (i) $\quad$ Iron deficiency anaemia & 27 & 30.68 \\
(ii) Anaemia of chronic disease & 15 & 17.04 \\
(iii) Primary polycythaemia & 5 & 5.68 \\
(iv) Abnormal bleeding / Disseminated & 5 & 5.68 \\
$\quad$ intravascular coagulation & & \\
(v) Autoimmune haemolytic anaemia & 4 & 4.54 \\
(vi) Non-Hodgkin's lymphoma & 4 & 4.54 \\
(vii) Multiple myeloma & 4 & 4.54 \\
(viii) Haemophilia & 3 & 3.41 \\
(ix) Haemochromatosis & 3 & 3.41 \\
(x) Hodgkin's disease & 3 & 3.41 \\
(xi) Acute myeloid leukaemia & 3 & 3.41 \\
(xii) Myelodysplastic syndrome & 3 & 3.41 \\
(xiii) Acute lymphoblastic leukaemia & 2 & 2.27 \\
(xiv) Aplastic anaemia & 2 & 2.27 \\
(xv) Idiopathic thrombocytopenic & 2 & 2.27 \\
(xvi) Megaloblastic anaemia & 1 & \\
(xvii) Chronic lymphocytic leukaemia & 1 & 1.14 \\
(xviii) Chronic myeloid leukaemia & 1.14 \\
\hline
\end{tabular}

Table.-II

Shows Haemoglobinopathies $(N=23)$

Types of Haemoglobinopathy No of patients Percentage

\begin{tabular}{lcc}
\hline Beta thalassaemia trait & 11 & 47.83 \\
Beta thalassaemia major & 5 & 21.74 \\
Haemoglobin E-trait & 4 & 17.39 \\
haemoglobin E-disease & 3 & 13.04 \\
\hline
\end{tabular}

\section{Discussion:}

Cancer is the second most killer in the world after cardio-vascular diseases ${ }^{12}$. About $13 \%$ of all death in the world is currently cause by cancer ${ }^{12}$. Where as in 2007 about $6 \%$ patient were suffering from diabetes mellitus which is growing as a silent killer ${ }^{12}$. When glycaemic status was considered 58.56\% (65 patients) showed diabetes mellitus along with haematological diseases in our study. Thus our pilot study supports studies of different countries 2,6-10,16-19,20-24,26-31,35,3740 and showed that, there is a correlation of diabetes mellitus with various haematological diseases ${ }^{13-17,20-}$ 24 . Table No-1 shows the distribution of 88 patients with haematological diseases except haemoglobinopathy. Among these 88 patients distribution of diseases, age and gender has correlation with studies in different counties 6-20, 26-37including Bangladesh $^{41,42}$. Figure-2 shows, 26 (29.54\%) with various clonal haematological malignancies, Figure-3 shows 16 patients $(18.18 \%)$ with bleeding disorders, autoimmune diseases and marrow aplasia and Figure4 shows $47(53.41 \%)$ out of 88 patients have deficiency anaemia, anaemia of chronic diseases and haemochromatosis. These results support studies in different countries ${ }^{6-20,26-37}$. Our study also suggests that iron deficiency anaemia and anaemia of chronic diseases were common among diabetic patients, which supports studies in various countries ${ }^{20}$. This study supports the increasing trend of cancer in female reported in other study ${ }^{37}$ including Bangladesh ${ }^{42}$.Our Study also shows $37 \%$ diabetic had various clonal haematological malignancies $26-34,36$. Figure no.1 shows the percentages of diabetic patients with both benign and malignant haematological diseases and supports other studies with leukaemia, lymphoma, myeloma and haemochromatosis along with diabetes mellitus 26-30, 31. Association between lymphoid neoplasm, blood dyscrasias, bleeding disorders, marrow aplasia, auto immune diseases and diabetic mellitus support studies in different countries which also reflected in our study $30,31,35-37$. In our study majority patients show diabetes mellitus along with benign or malignant haematological diseases which support studies in different countries ${ }^{13-16,20-24,26-29,} 30$ -37 . Table No-2 shows distribution of 23 patients out of $111(20.72 \%)$ were suffered from various types of haemoglobinopathy and among them 14 (60.87\%) 
were male and 9 (39.13\%) were female. In this study, age distribution of patient with haemoglobinopathy shows majority, that is, $60.87 \%$ were in $20-30$ years of age and were suffering from diabetes mellitus (11\%), which supports the study showed insulin deficiency, insulin resistance and iron overload had strong correlation with haemoglobinopathy and diabetes mellitus ${ }^{21-25}$. Thus in distribution of diseases, age and gender our study supports studies in different countries $21-24,38-40$. Our study showed $43 \%$ male had beta thalassaemia trait , $29 \%$ had beta thalassaemia major, $21 \%$ with haemoglobin $\mathrm{E}$ trait and $7 \%$ had haemoglobin E diseases; where as, 56\% female had beta thalassaemia trait, $22 \%$ had haemoglobin E diseases and $11 \%$ had beta thalassaemia major or haemoglobin E trait and support other studies including Bangladesh ${ }^{21-24,38-40}$. In this observational pilot study we observed that, diabetic patients with haematological diseases were anaemic and had more morbid state which show correlation with studies done in different countries ${ }^{13,}$ 1,4,21,22-25,27,29. This morbidity increases with chemotherapy which also correlates with other studies $31,32,35$. Thus our study supports studies done in Sweden ${ }^{7}$, USA ${ }^{11,37}$, Bangladesh ${ }^{41-43}$ and other studies $2,6,10,13-17,20-24,26-40$.

\section{Conclusion:}

This pilot study shows majority of benign and malignant haematological patients were suffering from diabetes mellitus. According to this study haematological diseases and malignancy except haemoglobinopthy, were predominant in female patients; where as, haemoglobinopthies were more in male group. So there is a need of further elaborative study to see if there any precipitating cause in patients suffering from diabetes mellitus with haematological diseases. There is also an immense need to maintain registry of these patients with a plan to establish state of art Haematology Department in all tertiary specialized hospitals including BIRDEM.

\section{Acknowledgement:}

We express our gratitude to all patients who were incorporated in this study.

\section{Reference:}

1. Ko C, Chaudhrys. The need for a multi disciplinary approach to cancer care. J Surg Res. 2002; 105 : 53-57.
2. Helen M. Psarakis. Clinical challenges in caring for patients with diabetes and cancer. Diabetes Sprectrum. 2006;19: 157-162.

3. Bloomgarden Z. Diabetes and cancer. Diabetes Care. 2001; 24: 780-781.

4. Bloomgarden Z. Second world congress on the insulin resistance syndrome : mediators, pediatric insulin resistance, the polycystic ovary syndrome and malignancy. Diabetic Care. 2005; 28: 1821-1830.

5. Balkau B, Kahn H, Courbon D, Eschwege E, Ducimetiere P. Hyperinsulinaemia predicts fatal liver cancer but is inversely associated with fatal cancer at some other sites. Diabetes Care. 2001; 24: 843-849

6. Richardson L, Pollack L. Therapy insight: Influence of type 2 diabetes on the development, treatment and outcomes of cancer. Nat Clin Pract Oncol 2005; 2: 48-53.

7. The national board of health and welfare centre for epidemiology. Cancer incidence in Sweeden.2004-2005.

8. World health organization. Diabetes Mellitus. Geneva, Switzerland: World Health Organization. WHO Fact Sheet 2002; 138 .

9. Gapstur SM, Gann PH, Lowe W et al. Abnormal glucose metabolism and pancreatic cancer mortality. J Ama Med Asso. 2000; 283: 2552-2558

10. V. Satya Suresh Attili, P P. Bapsy, Heman K. Dadhich, Ullas Batra, D. Iokanatha, K. Govind Babu. Impact of diabetes on cancer chemotherapy outcome: a retrospectrive analysis. International Journal of Diabetes in Developing Countries. 2007; 27(4):122-128

11. Saydah SH, Loria CM, Eberhardt MS, Brancati FL. Abnormal Glucose Tolerance and the risk of cancer death in the United States.Am J Epidemiol.2003; 157: 1092-100. 12. Ecgenia , Calle. Obesity and cancer, BMJ. 2007; 335: 1107-1108.

12. Khandaker MAK.Emerging regional threat of none comminicable diseases (Abstract) BCPS Joint Conference CPSP 2008 page 21-25. Bangladesh Collage of Physicians and Surguans. P-21-25

13. Maia J, Simkovic M, Pecka M. Haemocoagulation and renal insufficiency, haemocoagulation and type 2 diabetes mellitus. Vnitr lek. 2008; 54(5) : 452-456.

14. La Pez Y, Palmo MJ, Rifa NJ, Cuesta B, Pa iramo JA Measurement of prethrombotic markers in the assessment of acquired hypercoagulable states. Thromb Res.1999; 93(2) 71-78.

15. Weiser MA, Cabanillas ME, Konopleva M, Thomas DA, Pierce SA, Escalante CP etal. Relation between the duration of remission and hyperglycaemia during induction chemotherapy for acute lymphocytic leukaemia with a hyper fractionated cyclophosphamide, vincristine, daunorubicine and dexamethason / methotrexate -cytarabine regimen. Cancer. 2004; 100: 1179-1185. 
16. Roberson, Jessica R, Raju etal. Diabetes ketoacidosis during therapy for pediatric acute lymphoblastic leukaemia. Paediatric blood and cancer. 2008; 50(6): 1207-1212.

17. Antillon-ferreira carlos A, Dorantes-alvarez luis M, Coyoteestrada ninel etal. Diabetes mellitus secondary to chemotherapy in children with acute lymphoblastic leukaemia. Boletin Me'dico del hospital infantile de Me'xico. 2003; 60(3): 302-310.

18. Mentserrat E, Rozman C. Chronic lymphocytic leukaemia : present status. Ann Oncol. 1995; 6: 219-235.

19. Montserrat E, Bosch F, Rozman C. Treatment of B cell chronic lymphocytic leukaemia- current status and future perspective. J Intern Med. 1997; 242( suppl 740): 63-67.

20. Thron GW. Clinical consideration in the use of corticosteroids. N engl J Med. 1986; 274: 775.

21. Thomas DR. Anaemia in diabetic patients. Clin Geriatr Med. 2008; 24( 3): 529-540

22. Sundararaman Swaminathan, Vivian A. Fonseca, Muhammad G. Alam, Sudhir V. Shah. The role of iron in diabetes and its complications. Diabetes care. 2007. 30: 1926-1933.

23. GD Mclaren, WA Muir, RW Kellemeyer. Iron overload disorders: natural history, pathogenesis, diagnosis and therapy. Critical reviews in clinical laboratory sciences. 1983; 19(3): 205-266

24. Farmaki, Kalistheni, Angelopoulos etal. Effect of enhanced iron chelation therapy on glucose metabolism in patients with beta-thalassemia major. British Journal of haematology. 2006. 134(4) : 438-444.

25. Labropoulou-karatza C, Goritsas C, Fragopanagou H etal. High prevalence of diabetes mellitus among adult beta thalassemic patients with chronic hepatitis C. Eur J Gastroenterol Hepatol. Sept 1999; 11(9): 1033-1036.

26. Wilson, James G., Lindquist etal. Potential role of increased iron stores in Diabetes. American Journal of the Medical Sciences. 2003; 325(6): 332-339.

27. Hanblin TJ. Autoimmune complications of chronic lymphocytic leukaemia. Semin Oncol. 2006: 33: 230-239. 27. Sallah S, wan JY, hanrahan LR. Future development of Lymphoproliferative disorders in patients with auto immune haemolytic anaemia. Clin Cancer Res. 2001; 7: 791-794

28. Friedman G, Herrinton L. Obesity and multiple myeloma. Cancer causes Control 1994. 5: 479-483.

29. Kasim K, Levallois P, Abdous B, Auger P, Johnson KC. Lifestyle factors and the risk of adult leukaemia in Canada. Cancer causes and Control 2005; 16(5): 489-500.
30. Maclnnis RJ, English DR, Hopper JL, Giles GG. Body size and composition and the risk of lymphohaematopoietic malignancies. J Natl Cancer Inst 2005; 97(15): 1154-1157.

31. Adami HO, Mclaughlin J, Ekbom A, Berne C, Silverman D, Hacker D etal. Cancer risk in patients with diabetes mellitus. Cancer Causes Control. 1991; 2: 307-314

32. Daniel BT. Glycaemic crisis in patients with haematologic malignancies. Crit Care Nurs Clin North Am. 2000; 12(3): 297-305.

33. Drew Provan, Charles, R. J. Singer, Trevor Baglin, John Lilheyman. Oxford handbookof clinical haematology. 2nd ed. 2004, Oxford . New York. ( 33. Stowens D. Diabetes and neoplasia. Lancet. 1981; 2: 989.

34. T Natazuka,Y Mannbe, M Kono etal. Association betweeen non-insulin dependent diabetes mellitus and nonhodgkins lymphoma. BMJ.12 Nov 1994; 309: 1269.

35. Lisker SA, Brody JI, Beizer LH. Abnormal carbohydrate metabolism in patients with malignant blood dyscrasias. Am J Med Sci. 1996. 252: 282-288.

36. Brody JI, Merlie K. Metabolic and patients with diabetes mellitus: similarities to lymphocytes in chronic lymphocytic leukaemia and diabetes mellitus. Br J Haematol. 1970; 19 : 193-201.

37. Ahmedin Jemal, Rebecca Siegel, Elizabeth Ward, Taylor Murray, Jiaquan Xu, Michael J. Thun. Cancer Statistics, 2007.CA Cancer J Clin 2007; 57: 43-66.

38. Leung NT, Lau TK, Chung TKH. Thalassemia screening in pregnancy. Curr Opinion in Ob Gyn .2005; 17: 129-134.

39. Vichinsky EP. Changing patterns of thalassemia worldwide. Ann N Y Acad Sci. 2005; 1054:18-24.

40. Rahman M J, Rahman M H. Prevention \& control strategy of thalassemia in Bangladesh. The Orion Medical Journal. September-December 2003; Vol-16: 121-122.

41. Afrose S. Association of ABO Blood Group with Malignancies. Journal of Bangladesh College of Physicians and Surgeons.2005 January;23(1):25-31.

42. National Cancer Control Strategy and Plan of Action 20092015.Directorate General of Health Services, Ministry of health and family welfare with technical assistance from WHO. p1-76. http://www.whoban.org/pdf/CANCER\%20BOOK.pdf , accessed date 12.10.09.

43. Anaemia: A public health problem in Bangladesh. http://www.icddrb.org/publication.jsp?classificationID $=30$ \&pubID $=9654$ accessed date 12.10.09. 